\title{
NOTES
}

\section{Syntrophus buswellii gen. nov., sp. nov.: a Benzoate Catabolizer from Methanogenic Ecosystems}

\author{
D. O. MOUNTFORT, ${ }^{1} \dagger$ W. J. BRULLA, ${ }^{1}$ L. R. KRUMHOLZ, ${ }^{1}$ AND M. P. BRYANT ${ }^{1,2 *}$ \\ Department of Dairy Science ${ }^{1}$ and Department of Microbiology, ${ }^{2}$ University of Illinois, Urbana, Illinois 61801
}

Syntrophus buswellii, which was isolated from anaerobic digestor sludge and is present in aquatic sediments, is a motile, gram-negative, anaerobic rod-shaped organism that requires coculture with an appropriate hydrogenotroph for growth. This bacterium produces acetate, $\mathrm{CO}_{2}$, and $\mathrm{H}_{2}$ (or formate) from benzoate and, possibly, hydrocinnamate (phenyl-3-propionate). A detailed description is given.

Mountfort and Bryant (1) recently described the first anaerobe from methanogenic ecosystems that catabolizes benzoate in the absence of light, nitrate, or sulfate. This organism ferments benzoate according to the following equation:

$$
\begin{gathered}
\mathrm{C}_{7} \mathrm{H}_{5} \mathrm{O}_{2}^{-}+7 \mathrm{H}_{2} \mathrm{O} \rightleftharpoons 3 \mathrm{H}_{2}+\mathrm{HCO}_{3}^{-}+3 \mathrm{CH}_{3} \mathrm{COO}^{-}+3 \mathrm{H}^{+} \\
\Delta \mathrm{G}^{0^{+}}=+91 \mathrm{~kJ}
\end{gathered}
$$

Some formate may be produced in place of some $\mathrm{H}_{2}$ and $\mathrm{CO}_{2}$. The energetics of this reaction are such that the organism cannot be grown with benzoate unless a hydrogenotroph, such as Methanospirillum hungatei or Desulfovibrio sp., is present to maintain a very low concentration of soluble $\mathrm{H}_{2}$ (or formate) in the culture, and even then the growth rate is extremely low.

The organism which we used (1) in this study was designated Syntrophus buswellii strain DM-2 ${ }^{\mathrm{T}}$ (= DSM $2612 \mathrm{~A}^{\mathrm{T}}$ ) ( $T=$ type strain) in media containing sulfate and with Desulfovibrio added as the hydrogenotroph and also strain DM-3 (= DSM 2612B), which was the same culture except that $M$. hungatei $\mathrm{JF}-1^{\mathrm{T}}$ (= DSM $864^{\mathrm{T}}$ ) was added as the hydrogenotroph and sulfate was deleted; thus, Desulfovibrio sp. was present in much lower numbers in strain DM-3 cultures than in strain DM-2 $2^{\mathrm{T}}$ cultures (1). The methods and nnaterials which we used have been described previously (1).

Most of our data. have been published previously (1); however, thin sections (Fig. 1) indicated that the organism has an undulating outer membrane. Also, an identical morphotype was the most numerous organism present in further sludge enrichments with benzoate and phenyl-3-propionate (hydrocinnamate) but not in phenol or phenylacetate enrichments; the benzoate and hydrocinnamate enrichments rapidly adapted to benzoate or hydrocinnamate but not to phenylacetate or phenol (S. Barik, W. J. Brulla, and M. P. Bryant, Abstr. Annu. Meet. Am. Soc. Microbiol. 1983, I48, p. 147; unpublished data). Our results suggested that $S$. buswellii uses hydrocinnamate.

* Corresponding author.

$\dagger$ Present address: Cawthron Institute, Nelson, New Zealand.
$S$. buswellii differs from any previously described bacterium because it is anaerobic, does not contain visible pigments, does not utilize sulfate or nitrate as an electron acceptor, does not utilize sugars, ethanol, methanol, fatty acids, succinate, adipate, aspartate, phenylacetate, or phenol as an energy source, is inhibited by $\mathrm{H}_{2}$, and has monotrichous, polar flagella. In the studies conducted so far this organism required coculture with a hydrogenotroph for growth and catabolism of benzoate.

Direct microscopic cell counts of the strain DM-3 culture after full growth with $13.8 \mathrm{mM}$ benzoate indicated $2.7 \times 10^{9}$, $0.6 \times 10^{9}$, and $0.08 \times 10^{9}$ cells per $\mathrm{ml}$ of medium for $S$. buswellii, $M$. hungatei, and Desulfovibrio sp. strain G-11, respectively (1).

$S$. buswellii is placed in the family Bacteroidaceae (L. V. Holdeman, R. W. Kelley, and W. E. C. Moore, in N. R. Krieg, ed., Bergey's Manual of Systematic Bacteriology, 9th ed., in press) for the present as it is an anaerobic rod-shaped organism that is morphologically somewhat similar to $S u c$ cinimonas and is an obligate syntroph, as is Syntrophomonas, which is now included in this family.

Syntrophus gen. nov. Syntrophus (Syn'tro.phus. Gr. masc. n. syntrophos foster brother [one reared in the same house]; N. L. masc. n. Syntrophus one living syntrophically with another so that each produces a nutrient required by the other) cells are rod shaped, usually about 0.8 by 1 to $2 \mu \mathrm{m}$, have rounded ends, occur singly and in pairs, and are motile by means of monotrichous polar flagella in the early stages of growth. Resting stages, such as spores, are not known. Gram negative. Optimum temperature, near $37^{\circ} \mathrm{C}$. Chemoorganotrophic and anaerobic, with $\mathrm{H}_{2}$ inhibiting growth. Syntrophic with hydrogenotrophs. Benzoate is used as an energy source, with the production of acetate, $\mathrm{CO}_{2}$, and $\mathrm{H}_{2}$ (possibly formate). Sulfate or nitrate is not utilized as an electron acceptor, and no easily visible pigments are produced. Isolated from anaerobic digestor sludge and present in anaerobic aquatic sediments.

The type species is Syntrophus buswellii.

Syntrophus buswellii sp. nov. The description of Syntrophus buswellii (bus. wel'li.i. N.L. masc. gen. $\mathrm{n}$. buswellii in honor of A. M. Buswell, who first demonstrated degradation of benzoate in enrichments from methanogenic ecosystems [2]) is the same as the description given above for the genus, 
FIG. 1. Electron micrographs of thin sections of $S$. buswellii cells. Bars $=100 \mathrm{~nm}$. (a) Resolution of the cytoplasmic membrane (C), peptidoglycan layer (P), and outer membrane (O). (b) Transverse section exhibiting undulatory nature $(U)$ of the outer membrane. (c and d) Two possible stages occurring during septum formation (arrows) and cell division. Note the constrictive stage in (c). Cells were prepared for electron microscopy by fixation in glutaraldehyde-paraformaldehyde buffered with $0.067 \mathrm{M}$ cacodylate

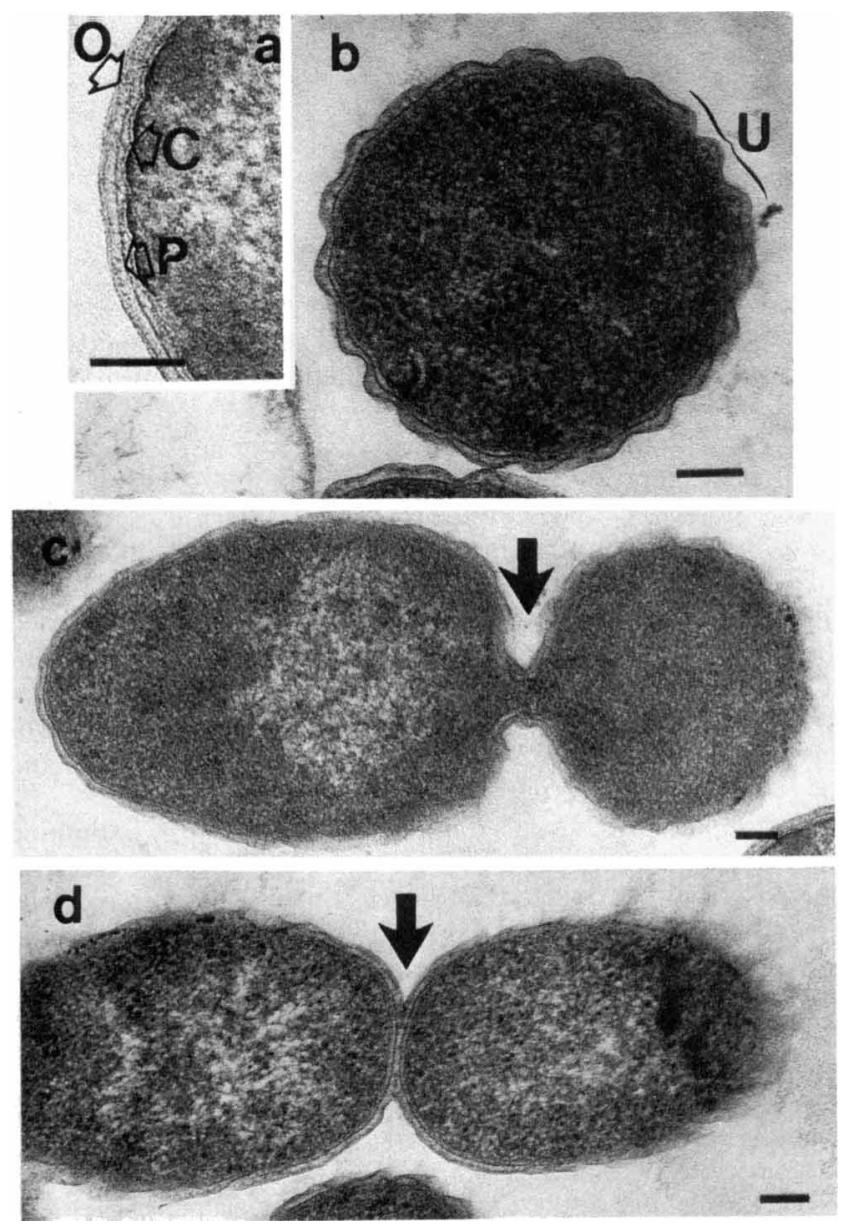

with the following additions. $S$. buswellii does not use acetate, adipate, aspartate, 4-amino-benzoate, butyrate, cellobiose, ethanol, fructose, glucose, $n$-heptanoate, $n$-hexanoate, succinate, methanol, phenylacetate, pimelate, propio-
(pH 6.5) and then in 1\% osmium tetroxide. The cells were enrobed in agar, dehydrated through an ethanol series, and embedded in Polybed 812 . Sections were stained with uranyl acetate and lead citrate and observed with a model JOEL $100 \mathrm{C}$ electron microscope. Sections also fixed with ruthenium red showed very little further staining (data not shown), discounting the presence of a common type of capsular material.

nate, or $n$-valerate and probably does not use cyclohexanone, ferulate, phenol, or vanillate, but does use benzoate as an energy source.

The type strain is strain DM-2 (= DSM 2612A and DSM 2612B).

The guanine-plus-cytosine content of the deoxyribonucleic acid has not been determined yet because of the necessity for coculture with other species, but this might be done if the deoxyribonucleic acid is sufficiently different from that of the hydrogenotroph or if the deoxyribonucleic acid can be obtained free of the deoxyribonucleic acid of the hydrogenotroph.

In cocultures $S$. buswellii has extremely long generation times of $166 \mathrm{~h}$ (strain DSM 2612B), $132 \mathrm{~h}$ (strain DSM 2612A), and $96 \mathrm{~h}$ (with fumarate and no sulfate added; (strain DSM 2612B) (1). We hypothesize that a shorter generation time of 50 to $70 \mathrm{~h}$ could be obtained by coculture of $S$. buswellii with Wolinella succinogenes and fumarate as the electron acceptor for $\mathrm{H}_{2}$ and formate oxidation. Experiments with two different species have indicated these shorter generation times (S. Barik and M. P. Bryant, unpublished data).

We are exceedingly pleased to acknowledge the help of $T$. $O$. MacAdoo, Virginia Polytechnic Institute and State University, in naming $S$. buswellii and the work of Hans Hippe and colleagues, Deutsche Sammlung für Mikroorganismen, in establishing it in a recognized culture collection. Use of the facilities of the Center for Electron Microscopy, University of Illinois, Urbana, is acknowledged.

This work was supported by research contract DE-ACO281ER10874 from the U.S. Department of Energy, by grant 35-331 from the U.S. Department of Agriculture, and by the Agricultural Experiment Station of the University of Illinois.

\section{LITERATURE CITED}

1. Mountfort, D. O., and M. P. Bryant. 1982. Isolation and characterization of an anaerobic syntrophic benzoate-degrading bacterium from sewage sludge. Arch. Microbiol. 133:249-256.

2. Tarvin, D., and A. M. Buswell. 1934. The methane fermentation of organic acids and carbohydrates. J. Am. Chem. Soc. 56:17511755 . 